\title{
FREE SPACE OPTICS EXPERIMENTAL SYSTEM - LONG TERM MEASUREMENTS AND ANALYSIS
}

\author{
Ján TÓTH, Luboš OVSENÍK, Ján TURÁN \\ Department of Electronics and Multimedia Telecommunications, Faculty of Electrical Engineering and Informatics, Technical \\ University of Košice, Park Komenského 13, 04001 Košice, Slovak Republic, tel. +55 602 4227, \\ e-mail: \{jan.toth, lubos.ovsenik, jan.turan\}@tuke.sk
}

\begin{abstract}
This paper considers Free Space Optics (FSO) systems. FSO availability and reliability is taken under the scope. FSO links operate within the infrared wavelength region. Lasers are used as light sources between two nodes to carry informational stream. FSO systems use Line of Sight (LOS) technology in order to maintain connection between two points. Weather conditions have quite significant impact on FSO operation in terms of availability and reliability. It is necessary to evaluate the air quality at the actual geographical location where FSO link is supposed to be placed. It is important to determine the impact of a light scattering, absorption, turbulence as well as a receiving power when dealing with FSO systems. Visibility has one of the most critical impacts on the quality of an optical transmission channel. Moreover, it is essential to monitor and store information about rain, snow and fog conditions. This paper introduces a device which measures all mentioned weather indicators such as a fog density, a relative humidity and a temperature. FSO availability and reliability estimation is based on measured data. These results evaluate weather conditions for Košice (a campuse of Technical University of Košice) in terms of FSO operation.
\end{abstract}

Keywords: availability, fog sensor, free space optics, long term measurements

\section{INTRODUCTION}

FSO is license free worldwide technology which offers full duplex connectivity between two points. It is called Free Space Optics (FSO) communication and it can be installed in less than one day. FSO uses infrared beams of light to provide optical broadband connection. Data rates go through range from hundreds of megabits to several gigabits [1]. An idea of FSO is very simple. It is based on connectivity optical wireless units (heads) which have transceivers. Each FSO head uses an optical source, lens or telescope to transmit beams of light through the atmosphere to receiving lens which receives the information signal [2, 3].

FSO system heavily depends on weather conditions because of constantly changing atmosphere behaviour. Atmospheric phenomena such as scattering, absorption, turbulences, diffraction and attenuations make losses which decreasing receiving power. So it is important to know an environment in which the FSO system is going to be installed. It can be done by monitoring of air quality. Ultimately the worst atmospherics phenomenon which influences FSO link is fog [4]. Fog consists of water droplets with $100 \mathrm{~nm}$ in diameter, which corresponds with using wavelengths in FSO systems [3]. It causes scattering and attenuation which have negative effects on infrared optical laser beam. Rain is formed from the water vapour contained in the atmosphere. It consists of water droplets whose form and number are variable in time and space. Rain attenuation is primarily due to the scattering phenomenon as in the case of aerosol [2]. Among other hydrometeors belong snow, hail, etc. Snow generally falls in the form of flakes or ice crystal aggregates. The flake diameters can reach $15 \mathrm{~mm}$. Attenuation is strongly related to humidity. For dry snow, attenuation can reach $40 \mathrm{~dB} / \mathrm{km}$ in the infrared region. Wet snow has attenuation varying from 4 to $8 \mathrm{~dB} / \mathrm{km}$. We don't consider the air pressure in this analysis, because we can direct measure liquid water content.

Chapter two describes experimental device for measuring atmosphere conditions in the campus of Technical University of Košice (TUKE). The third chapter is about FSO system which is installed in TUKE campus. The fourth chapter deals with availability calculations using FSO System Simulator. Conclusions are covered in chapter five.

\section{EXPERIMENTAL DEVICE FOR MEASURING ATMOSPHERE CONDITIONS}

This device was developed as the low cost measuring system which can measure three the most important parameters in atmosphere. Density of fog $[\mathrm{g} / \mathrm{m} 3]$, relative humidity [\%] and temperature $\left[{ }^{\circ} \mathrm{C}\right]$ represent three mentioned characteristics. All these sensors are built in the box which allows free movement of air flowing through.

Measured data is stored in a database which allows an easy and very flexible statistical data selection. During past few years several methods for storing sensor data were developed.

\subsection{Data stored in text files}

For sensor as a device communicates with computer through a standard RS232 interface. It turns out that measured data was saved and stored in *.txt files, Fig. 1.

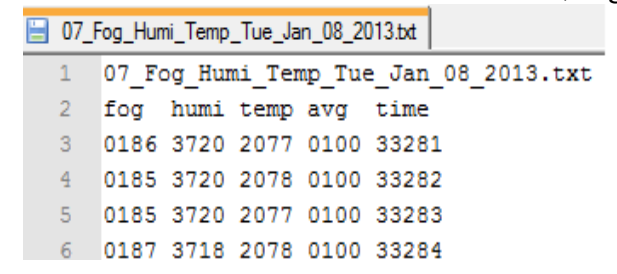

Fig. 1 Data stored in *.txt file . 
Data (raw fog, humidity and temperature values) is measured hundred times every second. The average value of all mentioned indicators are then inserted as a new row (in a text file) in the fashion which is shown in figure, Fig. 1. Each text file has a specific tag signed in a filename. This doesn't include only fog, humidity and temperature parameters moreover it saves a complete timestamp in a special format. This approach was not very convenient for data processing. Each text file has about 86400 lines. It is important to consider that this data was necessary to convert to real fog, humidity and temperature values in order to use these values to calculate a visibility parameter for FSO availability and reliability.

\subsection{Web base application with offline database}

The first simple approach (a text file) was innovated and replaced by a web based interface with "offline" MySQL database system. This system is called "FOG SENSOR, Statistical model v.1”, Fig 2, Fig. 3.

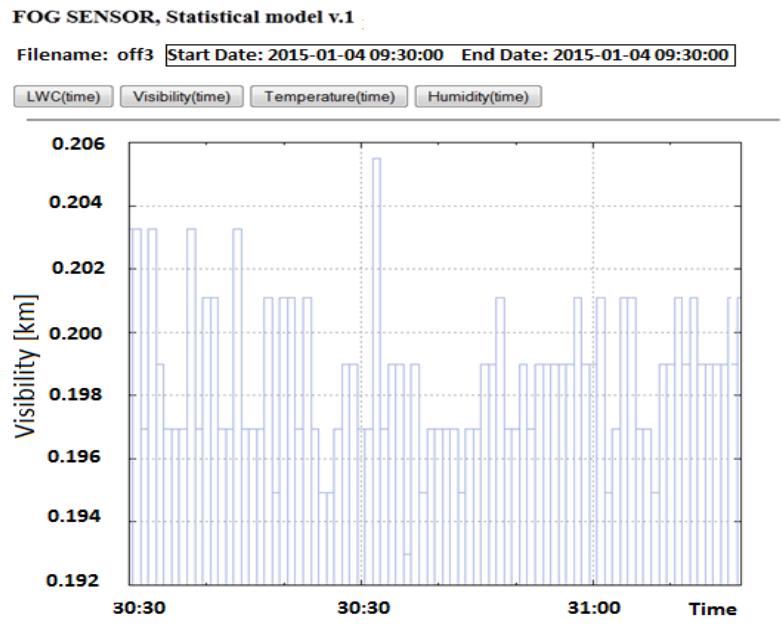

Fig. 2 An example of Visibility in "Web - based interface application with offline database".

\section{FOG SENSOR, Statistical model v. 1 \\ Filename: off4 Start Date: 2015-01-04 06:30:00 End Date: 2015-01-04 06:33:00}

LWC(time) Visibility(time) Temperature(time) Humidity(time)

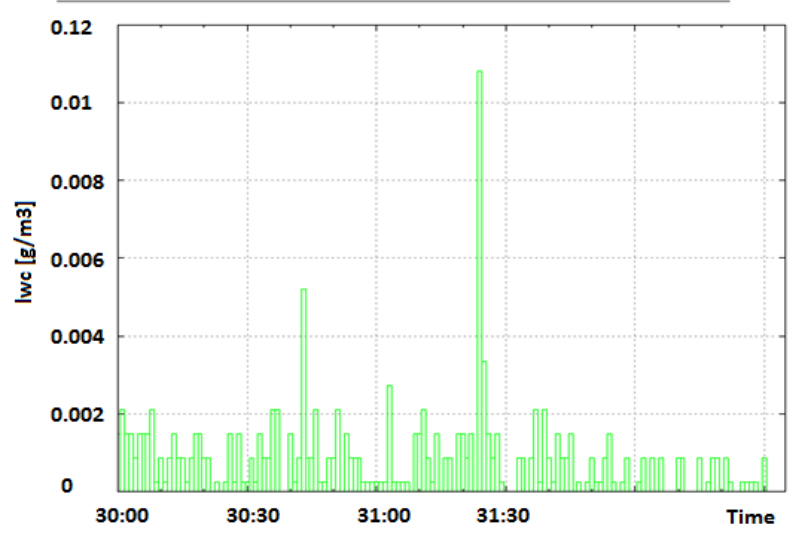

Fig. 3 An example of $L W C$ in "Web - based interface application with offline database".

It's easier to make any kind of mathematical operation in this database which is not the only advantage of this system.
This design allowed us to access measured values any time it is needed from any place because this application is fully accessible from internet. Table 1 shows the data structure stored in a database. This particular system was more appropriate for data evaluation, because data processing was faster and smoother than using *.txt files. Although this system is much more advanced than a *.txt files once, high speed communication systems strongly requires real time data processing.

Table 1 Web based application with offline database system

\begin{tabular}{|l|r|r|}
\hline & \multicolumn{2}{|c|}{ Processed fog and humidity values } \\
\hline timestamp & fog & humidity \\
\hline $\begin{array}{c}2013-03-1 \\
18: 22: 00\end{array}$ & 0.00459510775862069 & 106.991900 \\
\hline $\begin{array}{l}2013-03-14 \\
18: 22: 01\end{array}$ & 0.00459510775862069 & 106.958473 \\
\hline $2013-03-14$ & 0.00397347521551725 & 106.991900 \\
$18: 22: 02$ & 0.00770327047413794 & 106.991900 \\
$2013-03-14$ & & \\
$18: 22: 03$ & & \\
\hline
\end{tabular}

\subsection{Real time data processing}

The current software design saves data into MySQL database in real time, Fig 4. This is considered as a great advantage because data can be processed basically immediately.

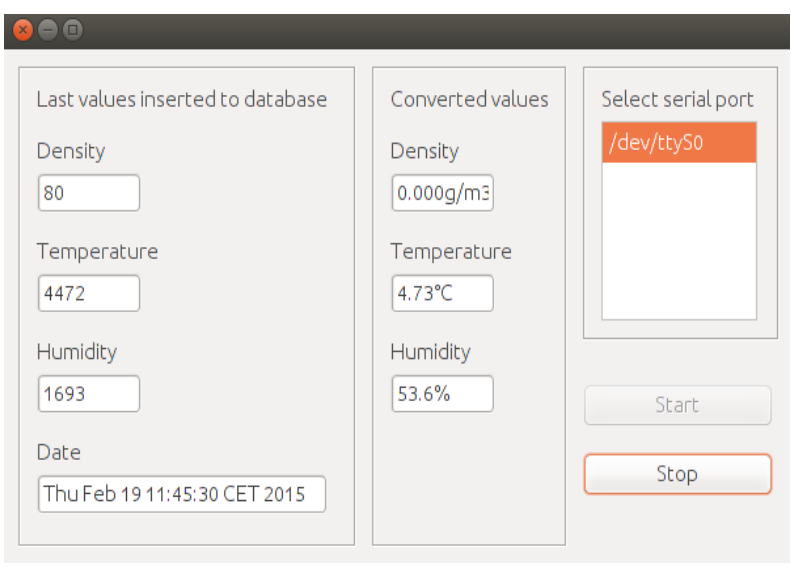

Fig. 4 Software application with an online database system.

Our application for real time data measurements is illustrated in Fig. 4. We can see the raw values on the left side and converted values in the middle of this window. Right part is called "Select serial port" and it contains all serial ports available in server.

All of the measured raw data is only numbers without unit. For calculation density of fog we use raw data from first column, by next equations:

$F=\left(D_{i} \cdot \frac{5}{1024}-0.87\right)=\frac{0.5}{2.9}$,

where $F$ is a density of fog and $D_{i}$ is Fog sensor measured value. If we want to get exact value of liquid water content we need to define a constant which helps us to convert 
value of fog to value of $L W C$. This constant is marked as $C$ and it is from ratio between the average liquid water content values $W_{i}$ and the Fog sensor output values $D_{i}[5]$.

$$
C=\frac{\sum_{i=1}^{n} W_{i}}{\sum_{i=1}^{n} D_{i}}=0.7384 \quad\left[\mathrm{~g} / \mathrm{m}^{3}\right]
$$

where $n$ is a number of samples during whole fog event. This constant is used to convert momentary sensor values $D_{i}$ to momentary LWC values [5]:

$$
L W C=F . C .
$$

One can derive an actual visibility value out of $L W C$ form (3). For the calculation we use the empirical formula for fog visibility as a function of fog density:

$V=d .(L W C)^{-0.65}$,

where $V$ is a visibility in $[\mathrm{km}]$ and parameter $d$ takes specific values for different fog conditions [6].

In this case, we have mentioned a stable and evolving fog for European area. It is characterized by stable air mass with cloud cover during the day, clear skies at night, light winds and moist air near the surface. These conditions often occur with a stationary high pressure area [7]. Thus parameter $d$ takes value which corresponds with Continental fog. Visibility is given by following equations:

$V=0.024(L W C)^{-0.65}$.

Relation between $L W C$ and visibility $V$ is illustrated in Fig. 5. Generally, we can say that fog event occurs when the visibility is lower than $1 \mathrm{~km}$.

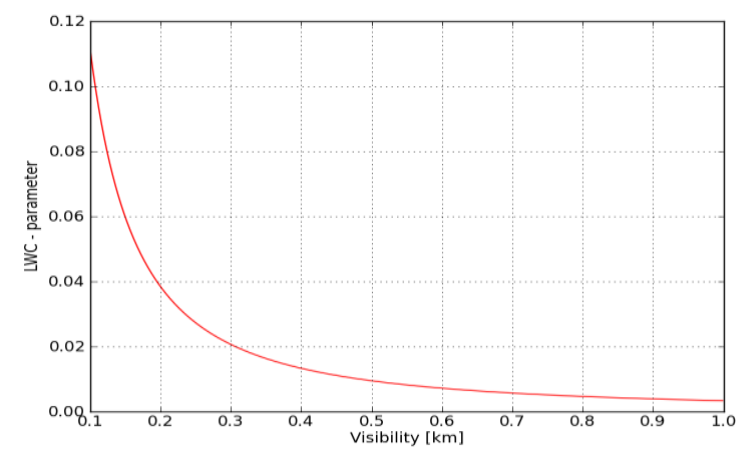

Fig. 5 LWC parameter as a function of Visibility [km].

\section{LIGHTPOINTE FREE SPACE OPTIC SYSTEM}

We have installed FSO link in campus of Technical University in Košice (TUKE). In Fig. 6 we can see a schematic connection between Laboratory of Optoelectronics Systems (LOS) and main building of TUKE.
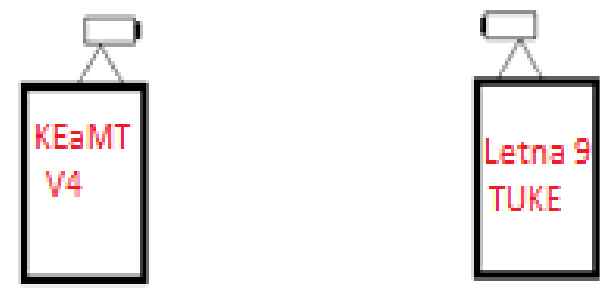

Fig. 6 Localization of FSO link in TUKE campus (distance between two builings is about $329 \mathrm{~m}$ ).

The FSO link is realized by Flighstrata 155E terminals. They provide full duplex communication with four laser beams technology. It offers better overall availability than one laser beam FSO systems. Flightstrata 155E terminals use $850 \mathrm{~nm}$ wavelengths. Detailed parameters of FSO terminals are summarized in Table 2 [8].

Edge value of visibility, is calculated by software package FSO SystSim. This software was created at TUKE. It calculates availability for specific systems by mathematic models and energy balance of FSO connections.

Table 2 FSO parameters

\begin{tabular}{|l|l|}
\hline Parameters & $\begin{array}{c}\text { Lightpointe } \\
\text { Flightstrata 155E }\end{array}$ \\
\hline Wavelenght & $850 \mathrm{~nm}$ \\
\hline Tx Power & $160 \mathrm{~mW}$ \\
\hline Rx Power(Sensitivity) & $-30 \mathrm{dBm}$ \\
\hline $\begin{array}{l}\text { Rx Diameter(Diameter } \\
\text { of receiving lens) }\end{array}$ & $8 \mathrm{~cm}$ \\
\hline Directivity (Divergence) & $2 \mathrm{mrad}$ \\
\hline
\end{tabular}

After entering inputs parameters of individual system, edge value of visibility is calculated. Edge visibility for 1 $\mathrm{km}$ long FSO link is $520 \mathrm{~m}$ for Lightpointe system Flightstrata 155E (Fig. 7).

After obtaining edge values for both systems we can analyse stored data from Fog sensor (Fig. 7). 

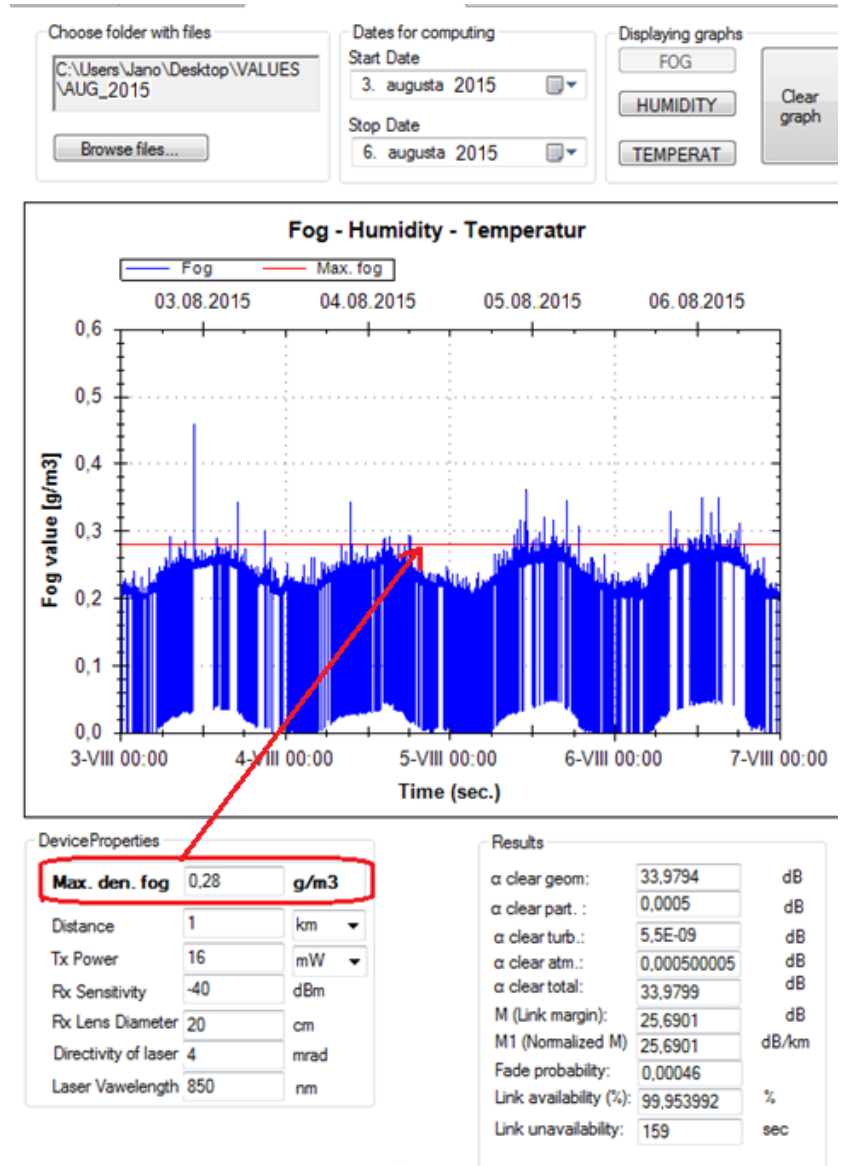

Fig. 7 Graph of water droplets event (Edge visibility value for 1 km FSO link with using Lightpointe system was calculated in Steady Model).

One can see, that edge (maximal) value of visibility is convert to parameter sign as "Max.den.fog" (i.e. Maximum density of fog) via equation (4), (Fig. 7). All values which are higher than threshold are saved in a text file made by FSO SysSim (Fig.8). Maximal visibility value is calculated in a previous step via Steady model software. This maximal visibility value is determined for a particular FSO device. "Max.den.fog" (extracted from maximal/edge visibility) is than taken as a specific threshold. This threshold is then compared with fog sensor values as shown in Fig. 7. Exceeded values from Fog sensor are recorded as shown in Fig. 8.

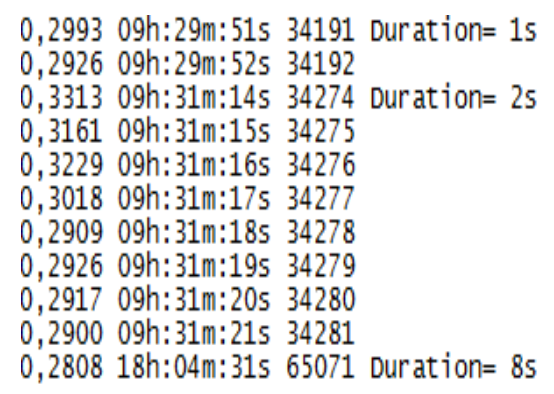

Fig. 8 LWC values higher than an acceptable threshold.

Each value which is entered in text file results in loss of optical connection. Number of fades is using to calculate availability of both FSO links during whole year.

\section{RESULTS}

Getting through the previous chapters we chronologically described and analyzed three different approaches to process and evaluate data from our experimental device. Gained link availability results are summarized in the following Fig. 9

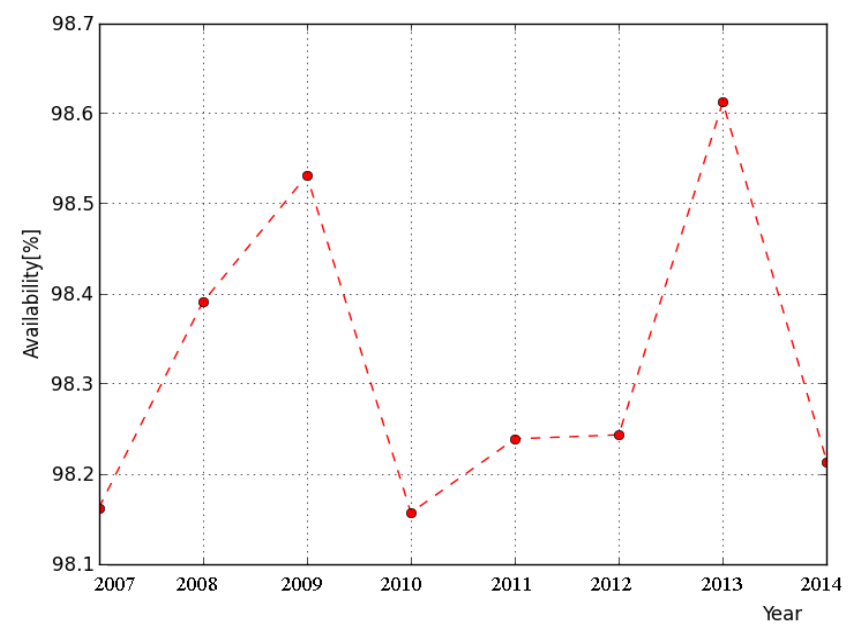

Fig. 9 FSO system availability pre actual years in range of 2007 - 2014.

We can find overall information about link availability for each particular year starting by 2007 until 2014 in Fig. 9. The total link availability during mentioned years for Lightpointe, Flightstrata $155 \mathrm{E}$ is $98,3184 \%$. As was mentioned above, for telecommunication purposes 99,999 $\%$ availability is needed. It is important to note that the distance of measuring chain and the first FSO transceiver is about 3 meters.

It is obvious that it is quite tough to achieve required availability in a real operation by using FSO link. That's why we will pay more attention to some kind of backup system to satisfy desired availability. One of the promising solution could be using of a backup radio link. There are potentially many acceptable antennas however $60 \mathrm{GHz}$ antenna seems to have the best properties for our purpose. Such connection is called hybrid FSO/RF link.

\section{CONCLUSIONS}

FSO systems as well as wireless communication systems are growing and highly progressive technologies which take place in nowadays communications systems. These technologies are capable of carrying satisfactory amounts of data through densely populated areas. The information is carried by the light beam from a laser which is propagating through a free space. It is important to have detailed data (fog, humidity and temperature) along transmission line. This data serve as essential input to set up and calculate appropriate FSO simulator parameters. Afterwards, one is able to calculate FSO availability and reliability for a particular link (in a campus of TUKE). Long term statistical measurement gives us helpful information ("a link footprint") about the actual geographical area. Furthermore, these results could act as 
the reference to decide if the FSO is beneficial and suitable in a particular location.

\section{ACKNOWLEDGMENTS}

This work was supported by project no. „006TUKE4/2014 - The Use of TUKE PON Experimental Model in Teaching". This work is also the result of the contract no. "APVV-0025-12 - Mitigation of Stochastic Effects in High-Bitrate All Optical Networks" supported by the Slovak Research and Development Agency.

\section{REFERENCES}

[1] FORIN, D. M. - INCERTI, G. - TOSI BELEFFI, G. M. - GEIGER, B. - LEITGEB, E. - NADEEM, F.: Free Space Optical Technologies, Trends in Telecommunications Technologies, March 2010.

[2] KIM, I. - KOREVAR, E.: Availability of Free Space Optics (FSO) and Hybrid FSO/RF Systems, Proc. SPIE, vol. 4530, 2001, 84-95.

[3] NADEEM, F. - KVICERA, V. - SALEEM, A. M. LEITGEB, E. et al.: Weather Effects on Hybrid FSO/RF Communication Link, IEEE Journal on Selected Areas in Communications, vol. 27, no. 9, December 2009, pp. 1687-1697.

[4] KOLKA, Z. - WILFERT, O. - BIOLKOVA, V.: Reliability of Digital FSO links in Europe, Int. J. Electronics, Communications, and Computer Engineering, vol. 1, no. 4, pp. 236-239, 2007.

[5] CSURGAI-HORVÁTH, L. - BITÓ, J: Fog Attenuation on V Band Terrestrial Radio and a Low Cost Measurement Setup, Future Network \& Mobile Summit, Florence, Italy, Paper \#47, June 2010.

[6] SHEIKH MUHAMMAD, S. - SALEEM AWAN, M. - REHMAN, A.: PDF Estimation and Liquid Water Content Based Attenuation Modeling for Fog in Terrestrial FSO Links. RADIOENGINEERING, Vol. 19, No. 2, June 2010.

[7] REYMANN, M. - PIASECKI, J. - HOSEIN, F. and col.: Meteorological Techniques, July 1998.

[8] Lighpointe, FlightStrata 155E- User Manual. Online: http://www.bauschnetworking.be/file/1061.

Received July 21, 2015 , accepted September 3, 2015

\section{BIOGRAPHIES}

Ján Tóth was born in Trebišov, Slovakia, on Jan. 16, 1988. He received his M.S degree from "Infoelectronics" University of Košice in 2012 at Department of Electronics and Multimedia Telecommunications, Faculty of Electrical Engineering and Informatics. He has started his PhD. studies at Technical university of Košice on September 2013. His main field of study is a research of full optical fibre networks and degradation factors as well as FSO systems.

Luboš Ovseník (doc., Ing., PhD.) received Ing. (MSc.) degree in radioelectronics from the University of Technology, Košice, in 1990. He received $\mathrm{PhD}$. degree in electronics from University of Technology, Košice, Slovakia, in 2002. Since February 1997, he has been at the University of Technology, Košice as Associate Professor for electronics and information technology. His general research interests include optoelectronic, digital signal processing, photonics, fiber optic communications and fiber optic sensors.

Ján Turán (Dr.h.c., prof., RNDr., Ing., DrSc.) received Ing. (MSc.) degree in physical engineering with honours from the Czech Technical University, Prague, Czech Republic, in 1974, and RNDr. (MSc.) degree in experimental physics with honours from Charles University, Prague, Czech Republic, in 1980. He received a CSc. (PhD.) and DrSc. degrees in radioelectronics from University of Technology, Košice, Slovakia, in 1983, and 1992, respectively. Since March 1979, he has been at the University of Technology, Košice as Professor for electronics and information technology. His research interests include digital signal processing and fiber optics, communication and sensing. 